This document is the Accepted Manuscript version of a Published Work that appeared in final form in Langmuir, copyright (c) American Chemical Society after peer review and technical editing by the publisher. To access the final edited and published work see:

https://dx.doi.org/10.1021/acs.langmuir.8b00642. 


\title{
Supported $\mathrm{Mn}_{3} \mathrm{O}_{4}$ nanosystems for hydrogen
}

\section{production through ethanol photoreforming}

\author{
Davide Barreca, ${ }^{\dagger}$ Lorenzo Bigiani, ${ }^{\ddagger}$ Matteo Monai ${ }^{\$}$ Giorgio Carraro, ${ }^{\ddagger}$ \\ Alberto Gasparotto, ${ }^{\star}$ Cinzia Sada, ${ }^{\|}$Sara Marti-Sanchez, ${ }^{\perp}$ Albert Grau-Carbonell, ${ }^{\perp}$ \\ Jordi Arbiol, ${ }^{,}, \#$ Chiara Maccato, ${ }^{*, *}$ and Paolo Fornasiero ${ }^{*}$,
}

${ }^{\dagger}$ CNR-ICMATE and INSTM, Department of Chemical Sciences, Padova University, Via F. Marzolo, 1 - 35131 Padova, Italy

$\ddagger$ Department of Chemical Sciences, Padova University and INSTM, Via F. Marzolo, 1 - 35131 Padova, Italy

\$ Inorganic Chemistry and Catalysis Group - Debye Institute for Nanomaterials Science, Utrecht University, Universiteitsweg, 99 - 3584 CG Utrecht, The Netherlands

${ }^{\S}$ Department of Chemical and Pharmaceutical Sciences, ICCOM-CNR and INSTM, Trieste University, Via L. Giorgieri, 1 - 34127 Trieste, Italy

" Department of Physics and Astronomy, Padova University and INSTM, Via F. Marzolo, 8 35131 Padova, Italy

${ }^{\perp}$ Catalan Institute of Nanoscience and Nanotechnology (ICN2), CSIC and BIST, Bellaterra, 08193 Barcelona, Catalonia, Spain

\# ICREA, Pg. Lluís Companys, 23 - 08010 Barcelona, Catalonia, Spain 


\begin{abstract}
Photoreforming promoted by metal oxide nano-photocatalysts is an attractive route for a clean and sustainable hydrogen generation. In the present work, we propose for the first time the use of supported $\mathrm{Mn}_{3} \mathrm{O}_{4}$ nanosystems, both pure and functionalized with $\mathrm{Au}$ nanoparticles (NPs), for hydrogen generation by photoreforming. The target oxide systems, prepared by chemical vapor deposition (CVD) and decorated with gold NPs by radio frequency (RF)-sputtering, were subjected to a thorough chemico-physical characterization and utilized for a proof-of-concept $\mathrm{H}_{2}$ generation in aqueous ethanolic solutions under simulated solar illumination. Pure $\mathrm{Mn}_{3} \mathrm{O}_{4}$ nanosystems yielded a constant hydrogen production rate of $10 \mathrm{mmol}$ $\mathrm{h}^{-1} \mathrm{~m}^{-2}$ even for irradiation times up to $20 \mathrm{~h}$. The introduction of $\mathrm{Au}$ NPs yielded a significant enhancement in photocatalytic activity, which decreased as a function of irradiation time. The main phenomena causing the Au-containing photocatalyst deactivation have been investigated by morphological and compositional analysis, providing important insights for the design of $\mathrm{Mn}_{3} \mathrm{O}_{4}$ based photocatalysts with improved performances.
\end{abstract}

KEYWORDS: nanosystems, $\mathrm{Mn}_{3} \mathrm{O}_{4}, \mathrm{Au}, \mathrm{H}_{2}$ production, photoreforming. 


\section{- INTRODUCTION}

The sustainable production of clean energy is a main open challenge in the search of sources alternative to fossil fuels, which are highly environmental polluting. ${ }^{1-3}$ In this regard, the use of largely available natural sources, such as water and solar light, to produce hydrogen, a high energy density carbon-neutral fuel, ${ }^{3-11}$ has received a progressively increasing attention. ${ }^{12-16}$ In this regard, the use of $\mathrm{TiO}_{2}$ in photoactivated hydrogen production has received a considerable attention due to its high efficiency, easy accessibility, low cost and chemical stability. ${ }^{10-12,17}$ Nevertheless, a major titania disadvantage is the high band-gap $\left(E_{\mathrm{G}} \approx 3.2 \mathrm{eV}\right)$, which requires UV photon excitation, accounting for only $3-4 \%$ of the incident solar radiation. ${ }^{9,12}$ As a consequence, great attention has been dedicated to the investigation of various metal oxide semiconductors as photocatalysts for water splitting, ${ }^{6,13,18-24}$ but the process efficiency is still far from industrial viability due to: $i$ ) the backward $\mathrm{H}_{2}$ and $\mathrm{O}_{2}$ reaction to yield water; ii) the recombination of photogenerated electron and holes, and iii) the need to improve photocatalyst sunlight absorption, to exploit solar illumination for real-world end-uses. ${ }^{12-13,18}$ To overcome the first two drawbacks, photoreforming processes, based on the use of aqueous solutions containing biomass-derived oxygenates (e.g. ethanol, glycerol,...), stand as a valuable option. ${ }^{12,18,25}$ The use of renewable feedstocks and solar energy to produce hydrogen is a much more sustainable approach than processes based on fossil fuels reforming. ${ }^{17}$ The main drawback is the generally low energy conversion efficiency, which can be enhanced by many possible strategies (e.g. material engineering, doping, sensitization), which are being extensively investigated. ${ }^{26}$ Converting biomass to $\mathrm{H}_{2}$ entails a higher energy content by weight with respect to the starting materials and the possibility to safely produce $\mathrm{H}_{2}$ in situ instead of distributing it over long distances. Moreover, the selective production of acetaldehyde instead of $\mathrm{CO}_{2}$ was observed using 
ethanol as a sacrificial agent over some photocatalysts, meaning that carbon emissions can be reduced while producing high-value chemicals in a green way.

To enhance photocatalyst sunlight harvesting, a proper choice and chemical tailoring of oxidebased semiconductors offers valuable opportunities to engineer their electronic and surface properties. $^{8,13-14,27}$ In this context, the functionalization with metal nanoparticles (NPs), such as $\mathrm{Au}, \mathrm{Ag}, \mathrm{Pt}$, has received a great attention to minimize the recombination of photogenerated electrons and holes, and enhance solar light harvesting. $5,8,12,20,23,28$

Among the possible photocatalyst materials, manganese oxides (e.g., $\mathrm{Mn}_{2} \mathrm{O}_{3}, \mathrm{Mn}_{3} \mathrm{O}_{4}, \mathrm{MnO}_{2}$ ) are very promising for bio-inspired water splitting, ${ }^{2-4,6,24,29-32}$ thanks to their environmentally friendly character, light absorption in the Vis spectral region and accessibility to various oxidation states, ${ }^{14,28,33-34}$ that have triggered their use as heterogeneous (photo)catalysts. So far, Mn oxide systems have been used in water (photo)oxidation, ${ }^{15-16,22,35-36}$ as well as in $\mathrm{H}_{2}$ generation by photoelectrochemical water splitting, ${ }^{6,14}$ along with $\mathrm{Mn}_{3} \mathrm{O}_{4}-\mathrm{NiO}^{3}$ and $\mathrm{Mn}_{2} \mathrm{O}_{3}-\mathrm{TiO}_{2}$ composite thin films. ${ }^{1}$ As concerns the improvement of $\mathrm{MnO}_{\mathrm{x}}$ (photo)catalytic performances through the controlled incorporation of metal nanoparticles, relevant examples include $\mathrm{Ag}-\mathrm{MnO}_{2}$ for organic dyes photodegradation, ${ }^{33}$ as well as $\mathrm{Pd}-\mathrm{MnO}_{2}$ nanorods ${ }^{23}$ and $\mathrm{Ag}-\mathrm{Mn}_{2} \mathrm{O}_{3}$ composite thin films ${ }^{28}$ for (photo)electrochemical water splitting. In particular, various efforts devoted to $\mathrm{Mn}_{3} \mathrm{O}_{4}$, a low cost spinel-type oxide endowed with high natural abundance and environmental compatibility, ${ }^{3,16,31,37}$ encompass the production of $\mathrm{M}-\mathrm{Mn}_{3} \mathrm{O}_{4}(\mathrm{M}=\mathrm{Pt}, \mathrm{Ag}, \mathrm{Au})$ powders as catalysts for various reactions ${ }^{37-40}$ and of $\mathrm{Pd}$ - and $\mathrm{Ni}-\mathrm{Mn}_{3} \mathrm{O}_{4}$ nanocomposites for water splitting. ${ }^{16,23}$ Nevertheless, apart a few cases, ${ }^{1,5,28,30,41-42}$ the majority of these studies have been devoted to powders instead of supported systems, whose implementation is highly required for practical applications, ${ }^{9,20,25}$ and no reports on $\mathrm{H}_{2}$ production by photoreforming from $\mathrm{Mn}_{3} \mathrm{O}_{4}$ 
nanosystems are available in the literature so far.

The possible large-scale use of $\mathrm{Mn}_{3} \mathrm{O}_{4}$-based catalysts in photoreforming processes depends on the tailored preparation of supported nanomaterials through cost-effective and potentially scalable processes. In this work, we present the preparation of supported $\mathrm{Mn}_{3} \mathrm{O}_{4}$-based nanosystems, grown on $\mathrm{Si}(100)$ substrates by means of a chemical vapor deposition (CVD) route, and their eventual functionalization with gold NPs by radio frequency (RF) sputtering (Figure 1, top panel) under mild conditions, avoiding any undesired alteration of the pristine $\mathrm{Mn}_{3} \mathrm{O}_{4}$ matrices. For the first time a proof-of-concept utilization of the target samples in solarassisted $\mathrm{H}_{2}$ production by photoreforming of aqueous ethanolic solutions is reported and discussed, also in terms of material activity and stability.

\section{- EXPERIMENTAL SECTION}

$\mathrm{Mn}_{3} \mathrm{O}_{4}$ nanodeposits were grown by $\mathrm{CVD}$ on $1 \times 1 \mathrm{~cm}^{2} \mathrm{Si}(100)$ substrates $\left(\mathrm{MEMC}{ }^{\circledR}\right.$, Merano, Italy). Basing on preliminary optimization experiments, deposition processes were performed in a pure $\mathrm{O}_{2}$ atmosphere at $400^{\circ} \mathrm{C}$ for $1 \mathrm{~h}$ (total pressure $=10.0$ mbar). As prepared $\mathrm{Mn}_{3} \mathrm{O}_{4}$ nanosystems were functionalized with Au NPs by means of RF-Sputtering from Ar plasmas using the following settings: $\mathrm{RF}$-power $=5 \mathrm{~W}$; deposition time $=30 \mathrm{~min}$; total pressure $=0.3$ mbar. Further details on the adopted instrumentation and processing parameters can be found in the Supporting Information, $\S \mathrm{S}-1$.

Field emission-scanning electron microscopy (FE-SEM) and energy dispersive X-ray spectroscopy (EDXS) analyses were performed by a Zeiss SUPRA 40VP apparatus equipped with an Oxford INCA x-sight X-ray detector, using primary beam voltages between 10 and 20 $\mathrm{kV}$. Images were recorded by collecting secondary and back-scattered electron signals (SE and 
BSE, respectively). The average nanodeposit thickness and NP diameters were evaluated through the Image ${ }^{\circledR}$ software (http://imagej.nih.gov/ij/, accessed November 2017), averaging over various independent measurements.

Atomic force microscopy (AFM) micrographs were recorded in tapping mode using an NT-MDT SPM Solver P47H-PRO instrument. After plane fitting, the root mean square (RMS) roughness values were obtained from the height profiles of $2 \times 2 \mu \mathrm{m}^{2}$ images.

Glancing incidence X-ray diffraction (GIXRD) measurements were carried out by a Bruker D8 Advance diffractometer, using a $\mathrm{CuK} \alpha \mathrm{X}$-ray source, at a fixed incidence angle of $1.0^{\circ}$.

High resolution-transmission electron microscopy (HR-TEM) micrographs were acquired with a FEI Tecnai F20 TEM operated at $200 \mathrm{kV}$. Cross sections of the samples were prepared by cutting them into slides followed by mechanical polishing and ion milling up to electron transparency. Compositional analysis was performed by combining high angle annular dark field-scanning TEM (HAADF-STEM) with EDXS.

A Perkin-Elmer $\Phi 5600$ ci spectrometer with an AlK $\alpha$ excitation source $(\mathrm{h} v=1486.6 \mathrm{eV})$ was used for X-ray photoelectron spectroscopy (XPS) analysis. Binding energy (BE) values were corrected for charging by assigning a $\mathrm{BE}$ of $284.8 \mathrm{eV}$ to the $\mathrm{C} 1 \mathrm{~s}$ signal of adventitious carbon. Least-square peak fitting was performed adopting Gaussian-Lorentzian peak shapes. ${ }^{9,27}$ Atomic percentages (at. \%) were determined using $\Phi$ V5.4A sensitivity factors. Further details are available in the Supporting Information, § S-1.

Secondary ion mass spectrometry (SIMS) analysis was carried out by a Cameca IMS $4 \mathrm{f}$ instrument, using a $\mathrm{Cs}^{+}$primary ion beam $(14.5 \mathrm{keV}, 20 \mathrm{nA})$ and negative secondary ion detection, accomplishing charge compensation by an electron gun. Rastering over a $150 \times 150$ $\mu \mathrm{m}^{2}$ area was performed, and secondary ions were sampled from a sub-region close to $8 \times 8 \mu \mathrm{m}^{2}$ 
to avoid crater effects. Beam blanking mode and high mass resolution configuration were adopted to improve in-depth resolution and avoid mass interference artifacts, respectively. The sputtering time in the abscissa of the recorded profiles was converted into depth values basing on the nanodeposit thickness data obtained by cross-sectional FE-SEM analyses (see below).

The photoreforming activity of bare and Au-loaded $\mathrm{Mn}_{3} \mathrm{O}_{4}$ specimens was evaluated using a previously described experimental apparatus, ${ }^{25}$ irradiating the samples with a solar simulator (LOT-Oriel). Specimens were mounted on a sample holder and placed on the bottom of the reactor, filled with $30.0 \mathrm{~mL}$ of ethanol:water 1:1 solution. The detection of $\mathrm{H}_{2}$ evolved from the working solution was performed by means of gas chromatography (see the Supporting Information, $\S \mathrm{S}-2.5$ for further details).

\section{- RESULTS AND DISCUSSION}

A preliminary characterization of the system nano-organization was carried out by means of FESEM. Pure $\mathrm{Mn}_{3} \mathrm{O}_{4}$ systems (Figures 1a-b) were characterized by the presence of highly interconnected faceted nanoaggregates [average lateral size $=(50 \pm 10) \mathrm{nm}$ ], whose assembly resulted in an uniform coverage of the $\mathrm{Si}(100)$ substrate and in a relatively compact crosssectional morphology [average thickness $=(170 \pm 10) \mathrm{nm}$ ]. After gold sputtering (Figure 1c), the chemical contrast yielded by BSE imaging provided evidence of brighter spots, related to the presence of dispersed low-sized gold NPs (mean diameter $\approx 6 \mathrm{~nm}$ ) evenly decorating the outermost $\mathrm{Mn}_{3} \mathrm{O}_{4}$ region. The corresponding cross-sectional micrograph (Figure 1d) revealed that no significant morphological and thickness modifications with respect to the pristine $\mathrm{Mn}_{3} \mathrm{O}_{4}$ took place after RF-sputtering, in agreement with previous studies. ${ }^{9,20}$ Accordingly, AFM micrographs (Supporting Information, Figure S1) showed very similar surface topographies, 
Figure 1. Sketches representing the target $\mathrm{Mn}_{3} \mathrm{O}_{4}$ and $\mathrm{Au} / \mathrm{Mn}_{3} \mathrm{O}_{4}$ nanodeposits. Plane-view and cross-sectional FE-SEM micrographs for $\mathrm{Mn}_{3} \mathrm{O}_{4}(\mathrm{a}, \mathrm{b})$ and $\mathrm{Au} / \mathrm{Mn}_{3} \mathrm{O}_{4}(\mathrm{c}, \mathrm{d})$ specimens. In the latter case, cross-sectional images were recorded by collecting SE (left) and BSE electrons (right). (f) Cross-sectional EDXS line-scans for $\mathrm{Au} / \mathrm{Mn}_{3} \mathrm{O}_{4}$ performed along the yellow line reported on micrograph (e). 
characterized by interconnected globular grains, and by RMS roughness values close to $1.0 \mathrm{~nm}$, irrespective of gold presence. Cross-sectional EDXS line scan analyses carried out in various sample regions (see representative examples in Figures 1e-f) enabled to ascertain the homogeneous formation of $\mathrm{Mn}_{3} \mathrm{O}_{4}$ through the whole deposit thickness. In fact, the intensities of $\mathrm{O}$ and $\mathrm{Mn}$ X-ray signals followed the same trend from the external surface up to the interface with the substrate. In addition, gold appeared to be mainly located in the system outermost layers, as also confirmed by TEM and SIMS analyses (see below).

The system structure was investigated by GIXRD, and the recorded patterns (Supporting Information, Figure S2) were characterized by the sole diffraction peaks of tetragonal $\alpha-\mathrm{Mn}_{3} \mathrm{O}_{4}$ (hausmannite) $^{43}$ with almost identical relative intensities of reflections before and after gold introduction, thanks to the mild conditions adopted for the sputtering process. ${ }^{20}$ The lack of any detectable gold reflection was mainly traced back to the high dispersion and relatively low content of Au-containing nanoaggregates. ${ }^{9}$

A deeper insight into the system nanostructure was obtained by TEM. Preliminary crosssectional HAADF-STEM (Z-contrast) images, along with EDXS elemental maps (Supporting Information, Figure S3) yielded thickness values in excellent agreement with FE-SEM results (see above), and revealed that carbon presence was limited to the outermost layers, suggesting that it mainly arose from external contamination (compare SIMS results). As can be observed, gold NPs were mainly concentrated in the near-surface nanodeposits regions, within a depth of $\approx$ $40 \mathrm{~nm}$. HR-TEM analyses evidenced the polycrystalline nature of Mn oxide nanoparticles, that appeared to be randomly oriented. Figure 2 a shows representative data for a [111] zone axisoriented aggregate of $\mathrm{Mn}_{3} \mathrm{O}_{4}$, crystallized in the tetragonal $I_{41} /$ amd crystal phase, with lattice constants $a=5.75 \AA$ and $c=9.42 \AA .^{2}$ In the HR-TEM micrograph, Moirée fringes arising from 

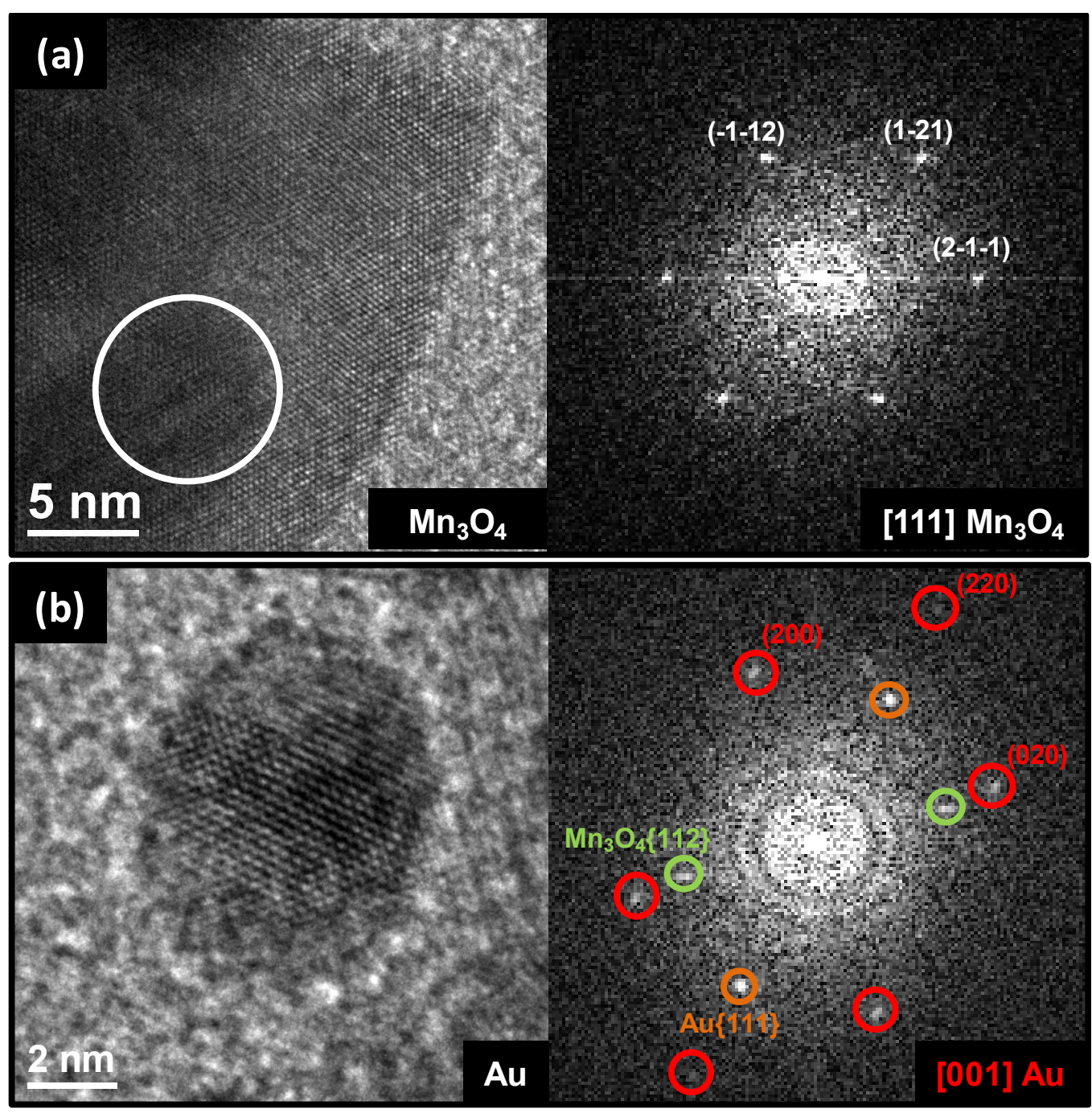

Figure 2. HRTEM micrographs and their corresponding power spectra (FFT) employed for phase identification of: (a) a [111] oriented $\mathrm{Mn}_{3} \mathrm{O}_{4}$ crystal in the polycrystalline $\mathrm{Mn}_{3} \mathrm{O}_{4}$ deposit; (b) an Au nanoparticle along its [001] zone axis. Spots marked in red correspond to the planes of $\mathrm{Au}[001]$ oriented crystal in zone axis. Green spot corresponds to $\mathrm{Mn}_{3} \mathrm{O}_{4}$ planes observed in the top right corner of the image. The orange spots have been identified as $\{111\}$ Au planes from the particle.

the presence of another overlapping $\mathrm{Mn}_{3} \mathrm{O}_{4}$ crystalline grain with a different orientation could be observed. The area showing the overlap with Moirée fringes is circled in white in Figure 2a. The absence of any appreciable preferential orientation and of any epitaxial relation between the 
$\mathrm{Si}(100)$ substrate and $\mathrm{Mn}_{3} \mathrm{O}_{4}$, due to the presence of the interfacial $\mathrm{SiO}_{\mathrm{x}}$ native oxide, was accompanied by an irregular grain morphology, with no net predominance of exposed facets. After RF-sputtering, polycrystalline Au NPs crystallizing in the cubic Fm3m phase (lattice constant $a=4.08 \AA$ ), with mean dimensions in agreement with those obtained by FE-SEM (see above), could be clearly observed (Figure 2b). In some cases, the Au nanoparticles exhibit twin defects and stacking faults, that result in different crystalline domains. ${ }^{44}$ The presence of different crystal domains is illustrated in Figure 2b, where (111) planes, corresponding to the selected orange spots in the power spectrum obtained from the same region, could be clearly observed. These (111) planes arise from a different crystal domain than the one found in [001] zone axis, which is responsible for the marked red spots in the power spectrum.

XPS analyses were carried out to investigate the system surface composition. Wide scan spectra (Supporting Information, Figure S4a) evidenced the presence of manganese, oxygen and, in the RF-sputtered sample, gold, along with adventitious carbon contamination $(<10$ at. \%). The O1s signal resulted from the concomitant contribution of lattice oxygen $(\mathrm{Mn}-\mathrm{O}-\mathrm{Mn}$ bonds; $\mathrm{BE}=$ $529.9 \mathrm{eV})^{30,40,45}$ and surface adsorbed oxygen/hydroxyl/carbonate species resulting from contact with the outer atmosphere ${ }^{9,19-20,28}(\mathrm{BE}=531.7 \mathrm{eV}, \approx 44 \%$ of the total O photopeak; Supporting Information, Figure S4b) As a consequence, the $\mathrm{O} / \mathrm{Mn}$ atomic ratio (see also Supporting Information, § S-2.4) was slightly higher than the stoichiometric one $(\approx 1.7)$. The analysis of the Mn2p signal shape and position $\left[\mathrm{BE}\left(\mathrm{Mn} 2 \mathrm{p}_{3 / 2}\right)=641.8 \mathrm{eV}\right.$; spin-orbit splitting $=11.6 \mathrm{eV},{ }^{16,31-}$ 32,35,39 Figure 3a], along with the spacing between the Mn3s multiplet splitting components (Supporting Information, Figure S4c; $5.4 \mathrm{eV}$ ), ${ }^{5,37,41}$ was indicative of $\mathrm{Mn}_{3} \mathrm{O}_{4}$ presence free from other Mn oxides, in accordance with the above discussed structural data. This conclusion was further corroborated by the energy difference between the $\mathrm{Mn} 2 \mathrm{p}_{3 / 2}$ maximum and the lowest $\mathrm{O} 1 \mathrm{~s}$ 

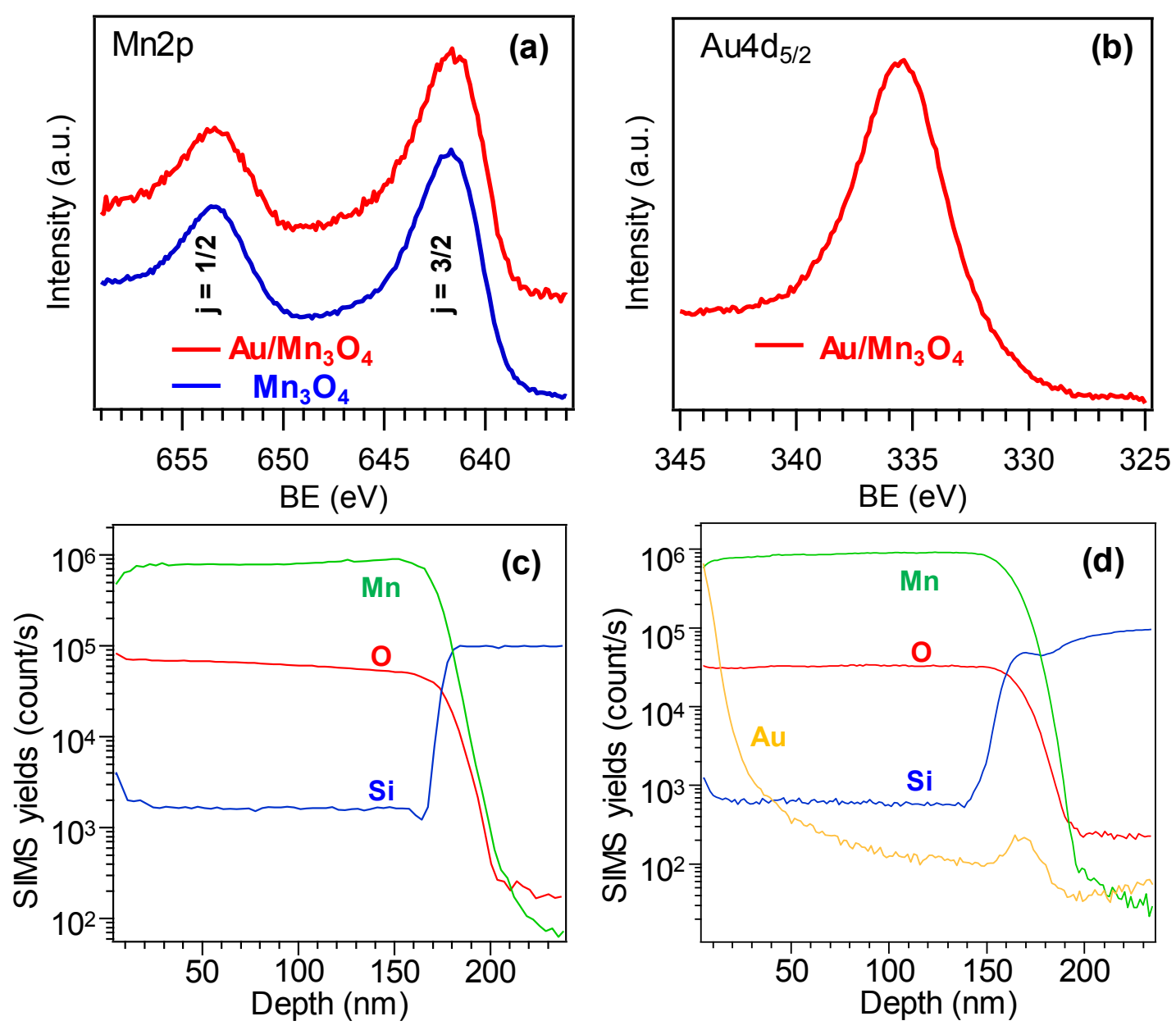

Figure 3. Surface $\mathrm{Mn} 2 \mathrm{p}$ (a) and $\mathrm{Au}_{4} \mathrm{~d}_{5 / 2}$ (b) photoelectron signals for $\mathrm{Mn}_{3} \mathrm{O}_{4}$ and $\mathrm{Au} / \mathrm{Mn}_{3} \mathrm{O}_{4}$ nanosystems. SIMS depth profiles for (c) $\mathrm{Mn}_{3} \mathrm{O}_{4}$ and (d) $\mathrm{Au} / \mathrm{Mn}_{3} \mathrm{O}_{4}$ specimens.

BE component, that corresponded to a value of $111.6 \mathrm{eV}$, in line with $\mathrm{Mn}_{3} \mathrm{O}_{4}$ presence. ${ }^{38,41-42}$ The overlap between the Mn3s signals and Au4f photoelectron peak (the most intense one for this element) prevented from detailed analyses of the latter signal (see the Supporting Information, $\S \mathrm{S}-2.4)$. To overcome this issue, the attention was focused on the interference-free Au4d $d_{5 / 2}$ photopeak [Figure $3 b ; B E\left(A u 4 d_{5 / 2}\right)=335.4 \mathrm{eV}$ ], which confirmed the occurrence of the sole $\mathrm{Au}(0) .{ }^{41,45}$ The average $\mathrm{Au} / \mathrm{Mn}$ surface atomic ratio was estimated to be 1.85 .

Important information on the in-depth chemical composition was obtained by SIMS analyses. In 
general, carbon contamination was estimated to be as low as tenths of ppm, a feature that, along with EDXS and XPS results, highlighted the purity of the obtained nanosystems. Irrespective of gold presence, representative SIMS depth profiles for both specimens (Figures 3c-d) evidenced almost constant and parallel $\mathrm{Mn}$ and $\mathrm{O}$ ionic yields throughout the investigated depth, with relatively sharp interfaces with the $\mathrm{Si}(100)$ substrate, indicating the even $\mathrm{Mn}_{3} \mathrm{O}_{4}$ formation across the entire deposit thickness. The principal differences between the two cases was related to the functionalization with $\mathrm{Au}$, whose ionic yield had an erfchian-type profile and underwent a progressive decrease at higher depth values. ${ }^{9,20}$ Overall, the presented results highlight that gold NPs were essentially concentrated in the outermost material region, and that their efficient and homogeneous dispersion resulted in an intimate contact with $\mathrm{Mn}_{3} \mathrm{O}_{4}$. Such a feature is highly beneficial in view of the target applications, since the involved heterojunctions are of critical importance in determining the system photocatalytic performances ${ }^{37}$ (see below).
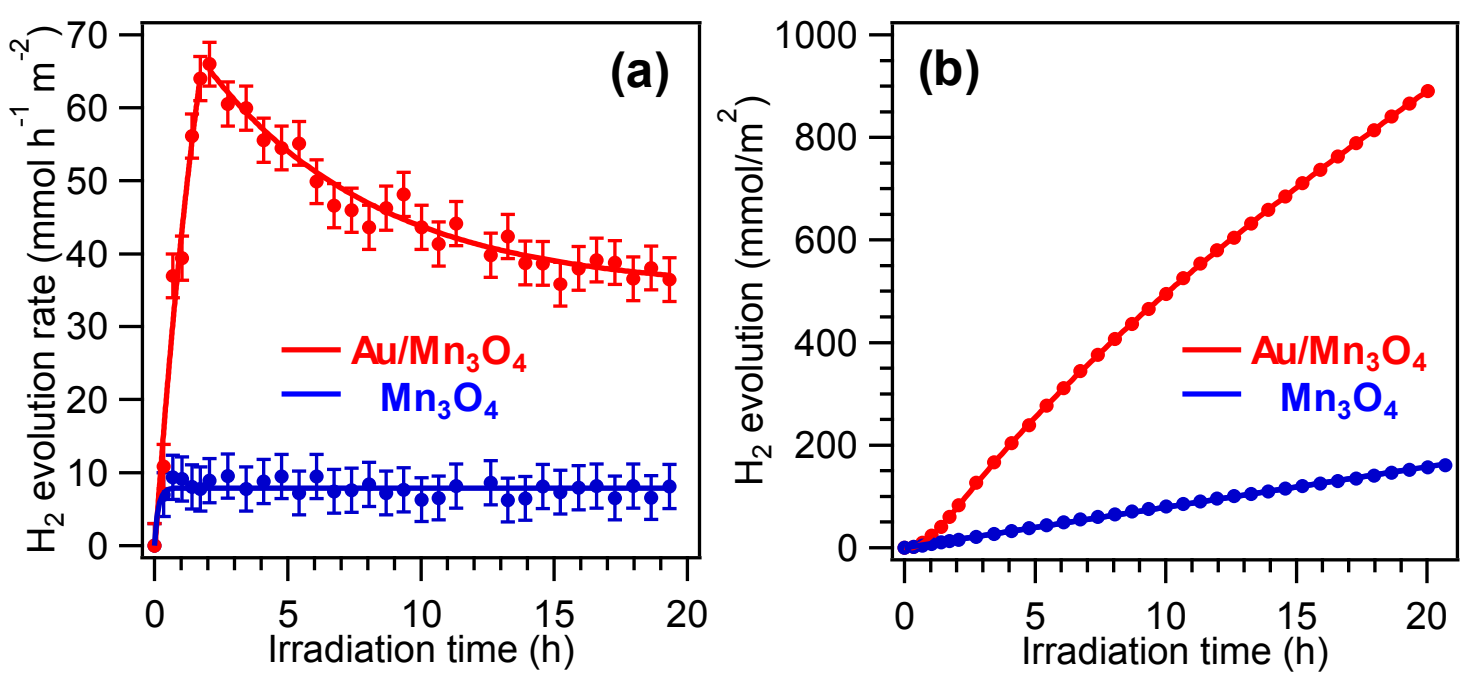

Figure 4. (a) $\mathrm{H}_{2}$ evolution and (b) integrated $\mathrm{H}_{2}$ production rates obtained during ethanol photoreforming over $\mathrm{Mn}_{3} \mathrm{O}_{4}$ and $\mathrm{Au} / \mathrm{Mn}_{3} \mathrm{O}_{4}$ photocatalysts under solar irradiation.

Hydrogen production by photoreforming was carried out in water/ethanol mixtures under 
simulated solar irradiation (Figure 4). The initial induction period $(<2 \mathrm{~h})$, typically observed in similar experiments, ${ }^{13}$ was related to a radiation-induced surface activation, as well as to the establishment of an equilibrium between by-products adsorbed on the catalyst surface and in the liquid/gas phase. ${ }^{9,19}$ As can be observed, bare $\mathrm{Mn}_{3} \mathrm{O}_{4}$ showed a constant $\mathrm{H}_{2}$ production over time up to $\approx 20 \mathrm{~h}$ of illumination (Figure $4 \mathrm{a}$ ), a result that, along with the linear trend of Figure $4 \mathrm{~b}$, evidenced an appreciable operational stability upon prolonged utilization. ${ }^{20}$ The solar-to-fuel efficiency (SFE; see the Supporting Information, § S-2.5) of the system (0.04\%) was remarkably enhanced by Au deposition, reaching a maximum (transient) value of $0.24 \%$, with an average of $0.10 \%$ over $60 \mathrm{~h}$. For $\mathrm{Au} / \mathrm{Mn}_{3} \mathrm{O}_{4}$, the obtained values compared favorably with those previously reported for $\mathrm{Fe}_{2} \mathrm{O}_{3}-\mathrm{TiO}_{2}$ and $\varepsilon-\mathrm{Fe}_{2} \mathrm{O}_{3}$ systems functionalized with $\mathrm{Au}$ NPs. ${ }^{9,20}$

Notably, $\mathrm{H}_{2}$ production rate of bare $\mathrm{Mn}_{3} \mathrm{O}_{4}$ was higher than that previously reported for supported $\mathrm{Fe}_{2} \mathrm{O}_{3},{ }^{19} \mathrm{Co}_{3} \mathrm{O}_{4},{ }^{21} \mathrm{CuO},{ }^{18} \mathrm{TiO}_{2},{ }^{9}$ and comparable to that of $\mathrm{Au}-\mathrm{TiO}_{2}{ }^{9}$ nanomaterials under analogous irradiation conditions. After functionalization with Au NPs, a significant improvement of the observed photoactivity took place, resulting in hydrogen production rates that compared favorably not only with those reported for $\mathrm{Cu}_{x} \mathrm{O}-\mathrm{TiO}_{2}-\mathrm{Au},{ }^{13} \varepsilon-\mathrm{Fe}_{2} \mathrm{O}_{3}-\mathrm{Au}^{20}$ and $\mathrm{Fe}_{2} \mathrm{O}_{3}-\mathrm{TiO}_{2}-\mathrm{Au}^{9}$ nanocomposites, but even with those of state-of-the-art titania-based photocatalysts. ${ }^{46-47}$

The significance hold by the present results is further corroborated by the use of supported nanomaterials instead of the corresponding powdered systems $s^{9,13,20-21}$ and by the absence of additives used in previous studies, such as photosensitizers $\left(\text { e.g. }\left[\operatorname{Ru}(\mathrm{bpy})_{3}\right]^{2+}\right)^{2,22,29,36}$ or expensive/toxic co-catalysts (e.g. $\mathrm{Pd}, \mathrm{Pt}, \mathrm{RuO}_{2}$ and $\left.\mathrm{IrO}_{2}\right) .{ }^{12,16,27,31,42}$

Beside the inherent $\mathrm{Mn}_{3} \mathrm{O}_{4}$ catalytic activity, the promising performances of the target systems can be traced back to the presence of: i) voids extending into the systems structure (see above), 
resulting in an exposure to the reaction environment even of the internal material surface; ii) an intimate $\mathrm{Au} / \mathrm{Mn}_{3} \mathrm{O}_{4}$ contact, of key importance in order to exploit their electronic interplay. ${ }^{9}$ The improved $\mathrm{Au} / \mathrm{Mn}_{3} \mathrm{O}_{4}$ activity can be in fact attributed to the formation of $\mathrm{Au} / \mathrm{Mn}_{3} \mathrm{O}_{4} \mathrm{Schottky}$ junctions, ${ }^{8,17,23}$ promoting an improved separation of photogenerated charge carriers and rendering photoproduced electrons more available for $\mathrm{H}_{2}$ production. In addition, Au NPs localized surface plasmon resonance (LSPR), i.e. the collective oscillation of free electrons induced by incident radiation, ${ }^{9,20}$ can result in an enhanced sunlight harvesting, ${ }^{23,28,48-49}$ further contributing to the observed $\mathrm{H}_{2}$ yield increase.

The possible mechanism of the overall process is described in the Supporting Information, section S-2.5. In the present study, acetaldehyde was the only product detected in the liquid phase, as a result of ethanol oxidation by photogenerated holes. No other products such as CO, oxygen, methane or formaldehyde were observed in the gas phase. The formation of molecular hydrogen is obtained through the reduction of adsorbed $\mathrm{H}^{+}$ions by photogenerated electrons. ${ }^{9,12,19}$ On the other hand, production of oxygen by water splitting was not observed, highlighting that water oxidation does not directly contribute to hydrogen production. This result can be explained taking into account that, from a thermodynamical point of view, the reaction of water to produce oxygen is more demanding $\left(\Delta \mathrm{G}^{0}{ }_{298 \mathrm{~K}}=237 \mathrm{~kJ} \times \mathrm{mol}^{-1}\right)^{12}$ than the oxidation of ethanol to acetaldehyde $\left(\Delta \mathrm{G}^{0}{ }_{298 \mathrm{~K}}=36 \mathrm{~kJ} \times \mathrm{mol}^{-1}\right) .{ }^{50}$

On the basis of the above results, a possible mechanism for the observed activity enhancement upon $\mathrm{Au}$ introduction is proposed in Supporting Information, Figure S5. Upon simulated solar illumination, photon absorption results in the formation of electron-hole pairs, with the promotion of electrons into the $\mathrm{Mn}_{3} \mathrm{O}_{4}$ conduction band. The presence of $\mathrm{Au}$ nanoparticles on $\mathrm{Mn}_{3} \mathrm{O}_{4}$ can increase the separation between charge carriers, since photogenerated electrons can 
be captured by the noble metal, whose Fermi level is lower in energy than the conduction band edge. Thanks to the formation of the $\mathrm{Au} / \mathrm{Mn}_{3} \mathrm{O}_{4}$ Schottky junctions and intimate contact, the electrons transferred to $\mathrm{Au}$ NPs can boost $\mathrm{H}^{+}$reduction to $\mathrm{H}_{2}$ (see the Supporting Information, equation (S9) $)^{10}$ making the process more efficient than over $\mathrm{Mn}_{3} \mathrm{O}_{4}$. Photoproduced holes, localized in $\mathrm{Mn}_{3} \mathrm{O}_{4}$ valence band, can promote photooxidation processes, ${ }^{9,20}$ either directly or by $\mathrm{OH}^{\cdot}$ radicals. $^{50}$

Despite the advantageous performance improvement enabled by Au NPs introduction, the experimental data in Figure 4 show that the activity of $\mathrm{Au} / \mathrm{Mn}_{3} \mathrm{O}_{4}$ photocatalysts underwent a progressive decrease for prolonged irradiation times. In order to get a further insight into this phenomenon, the $\mathrm{Au} / \mathrm{Mn}_{3} \mathrm{O}_{4}$ photocatalyst was tested in sequential catalytic runs using fresh ethanol solutions each time, and rinsing the catalyst with water and ethanol after every run. As can be observed in Supporting Information, Figure S6, since the deactivation proceeded even after washing and in fresh reaction mixtures, the activity loss was unlikely to be related to poisoning by reaction byproducts. In addition, $\mathrm{Au}$ oxidation and photocorrosion with concomitant gold ion dissolution were not expected, since $\mathrm{Au}$ is a noble metal with a high reduction potential. ${ }^{51}$ This prediction was indeed confirmed by quantitative EDXS analyses before and after photocatalyst utilization, that yielded typical values very close to $5.0 \%$ in both cases. In order to gain a deeper insight into the observed behavior, FE-SEM analyses were performed on a representative $\mathrm{Au} / \mathrm{Mn}_{3} \mathrm{O}_{4}$ system subjected to various utilization cycles (Supporting Information, Figure S7). As can be observed by the presented micrographs, the main morphological modification occurring after photocatalytic tests was the increase of Au NP mean size, from the pristine value of $\approx 6 \mathrm{~nm}$ up to $\approx 15 \mathrm{~nm}$. The consequent decrease of the surface-tovolume ratio is considered to be the main cause accounting for the decrease in $\mathrm{Au} / \mathrm{Mn}_{3} \mathrm{O}_{4}$ 
photoactivity upon prolonged illumination. Indeed, electrons generated by LSPR have a very short lifetime, in the time scale of femtoseconds, ${ }^{8,48}$ and, in order to take part to the photocatalytic process, they have to survive during the above discussed transfer across the interfacial Schottky barrier. As a matter of fact, an increase of Au nanoparticle size causes not only a LSPR decrease, ${ }^{23,49}$ but also a lower interfacial contact between $\mathrm{Au}$ and $\mathrm{Mn}_{3} \mathrm{O}_{4}$, resulting in a less efficient electron transfer and, ultimately, in a decrease of hydrogen production rate, as experimentally observed. $^{23}$

\section{CONCLUSIONS}

In summary, we have reported on the vapor phase deposition of supported $\mathrm{Mn}_{3} \mathrm{O}_{4}$-based nanophotocatalysts for hydrogen photogeneration from aqueous ethanol solutions. In particular, after the initial CVD growth of $\mathrm{Mn}_{3} \mathrm{O}_{4}$ on $\mathrm{Si}(100)$, functionalization with gold by RF-Sputtering under mild conditions enabled the fabrication of $\mathrm{Au} / \mathrm{Mn}_{3} \mathrm{O}_{4}$ specimens. The samples were composed by single-phase and high-purity hausmannite $\mathrm{Mn}_{3} \mathrm{O}_{4}$, with small $\mathrm{Au}$ nanoparticles uniformly dispersed on manganese oxide nanoaggregates in the case of $\mathrm{Au} / \mathrm{Mn}_{3} \mathrm{O}_{4}$ samples. The target systems were tested for the first time in photocatalytic hydrogen generation, and their functional performances turned out to be critically affected by their actual composition. For bare $\mathrm{Mn}_{3} \mathrm{O}_{4}$, the obtained stable hydrogen production rates were higher than those reported for various supported oxide nanomaterials, whereas $\mathrm{Au} / \mathrm{Mn}_{3} \mathrm{O}_{4}$ composites displayed improved performances that compared favorably with state-of-the-art $\mathrm{TiO}_{2}$ photocatalysts. This improvement was rationalized in terms of an enhanced charge carrier separation at the interface between manganese oxide and gold, whose close contact had a beneficial role in boosting $\mathrm{H}_{2}$ yields thanks also to an improved solar light harvesting. The results obtained as a proof-of- 
concept in this work may serve as a useful guide in the design of noble metal-manganese oxides for a variety of photo-assisted processes, encompassing hydrogen generation using more sustainable oxygenates, such as glycerol, and photocatalytic $\mathrm{CO}_{2}$ reduction. Attention will be also dedicated to the growth of $\mathrm{Mn}_{3} \mathrm{O}_{4}$-based nanomaterials on conductive glass substrates for the preparation of photoanodes to be used in photoelectrochemical cells aimed at water splitting triggered by solar irradiation. Nevertheless, the progressive decay of $\mathrm{Au} / \mathrm{Mn}_{3} \mathrm{O}_{4}$ photoactivity for prolonged illumination periods, that was related to $\mathrm{Au}$ nanoparticle aggregation during irradiation, highlights the need of further experimental efforts to produce systems with enhanced stability, for instance by coverage of $\mathrm{Au} / \mathrm{Mn}_{3} \mathrm{O}_{4}$ surfaces with an ultra-thin $\mathrm{TiO}_{2}$ layer. Progresses in this direction will be the object of our future attention.

\section{aSSOCIATED CONTENT}

Supporting Information. Details on synthesis, AFM, XRD, HAADF-STEM, EDXS, XPS and photoreforming measurements for the as-prepared materials; morphological and compositional data collected after hydrogen production tests. This material is available free of charge via the Internet at http://pubs.acs.org.

\section{AUTHOR INFORMATION}

\section{Corresponding Authors}

* phone: +39-0498275234; e-mail: chiara.maccato@unipd.it; ORCID: 0000-0001-6368-5754

(C.M.); phone: +39-0405583973; e-mail: pfornasiero@units.it; ORCID: 0000-0003-1082-9157 (P.F.).

\section{Author Contributions}


The manuscript was written through contributions of all authors. All authors have given approval to the final version of the manuscript.

\section{Notes}

The authors declare no competing financial interest.

\section{ACKNOWLEDGMENTS}

This work was supported by funding from Padova University DOR 2016-2017, P-DiSC \#03BIRD2016-UNIPD projects and ACTION post-doc fellowship, as well as from Trieste University (FRA2015 project). Funding from "Programa Internacional de Becas "la Caixa"Severo Ochoa" and from Generalitat de Catalunya 2017 SGR 327 and MINECO ENE201785087-C3 are also acknowledged. ICN2 acknowledges support from the Severo Ochoa Program (MINECO, Grant SEV-2013-0295) and the CERCA Programme/Generalitat de Catalunya. Part of the present work has been performed in the framework of Universitat Autònoma de Barcelona Materials Science PhD program. 


\section{REFERENCES}

(1) Mansoor, M. A.; Mazhar, M.; McKee, V.; Arifin, Z. $\mathrm{Mn}_{2} \mathrm{O}_{3}-4 \mathrm{TiO}_{2}$ Semiconducting Composite Thin Films for Photo-electrochemical Water Splitting. Polyhedron 2014, 75, 135-140.

(2) Menezes, P. W.; Indra, A.; Littlewood, P.; Schwarze, M.; Göbel, C.; Schomäcker, R.; Driess, M. Nanostructured Manganese Oxides as Highly Active Water Oxidation Catalysts: A Boost from Manganese Precursor Chemistry. ChemSusChem 2014, 7, 22022211.

(3) Rahaman, H.; Barman, K.; Jasimuddin, S.; Ghosh, S. K. Hybrid $\mathrm{Mn}_{3} \mathrm{O}_{4}-\mathrm{NiO}$ Nanocomposites as Efficient Photoelectrocatalysts Towards Water Splitting Under Neutral pH Conditions. RSC Adv. 2016, 6, 113694-113702.

(4) Frey, C. E.; Kurz, P. Water Oxidation Catalysis by Synthetic Manganese Oxides with Different Structural Motifs: A Comparative Study. Chem. Eur. J. 2015, 21, 14958-14968.

(5) Huynh, M.; Shi, C.; Billinge, S. J. L.; Nocera, D. G. Nature of Activated Manganese Oxide for Oxygen Evolution. J. Am. Chem. Soc. 2015, 137, 14887-14904.

(6) Roger, I.; Shipman, M. A.; Symes, M. D. Earth-Abundant Catalysts for Electrochemical and Photoelectrochemical Water Splitting. Nat. Rev. Chem. 2017, 1, 0003.

(7) Thenuwara, A. C.; Shumlas, S. L.; Attanayake, N. H.; Cerkez, E. B.; McKendry, I. G.; Frazer, L.; Borguet, E.; Kang, Q.; Zdilla, M. J.; Sun, J.; Strongin, D. R. CopperIntercalated Birnessite as a Water Oxidation Catalyst. Langmuir 2015, 31, 12807-12813.

(8) Naldoni, A.; Montini, T.; Malara, F.; Mróz, M. M.; Beltram, A.; Virgili, T.; Boldrini, C. L.; Marelli, M.; Romero-Ocaña, I.; Delgado, J. J.; Dal Santo, V.; Fornasiero, P. Hot Electron Collection on Brookite Nanorods Lateral Facets for Plasmon-Enhanced Water Oxidation. ACS Catal. 2017, 7, 1270-1278.

(9) Barreca, D.; Carraro, G.; Gasparotto, A.; Maccato, C.; Warwick, M. E. A.; Toniato, E.; Gombac, V.; Sada, C.; Turner, S.; Van Tendeloo, G.; Fornasiero, P. Iron-Titanium Oxide Nanocomposites Functionalized with Gold Particles: From Design to Solar Hydrogen Production. Adv. Mater. Interfaces 2016, 3, 1600348.

(10) Chiarello, G. L.; Selli, E.; Forni, L. Photocatalytic Hydrogen Production over Flame Spray Pyrolysis-Synthesised $\mathrm{TiO}_{2}$ and $\mathrm{Au} / \mathrm{TiO}_{2}$. Appl. Catal., B 2008, 84, 332-339. 
(11) Daskalaki, V. M.; Kondarides, D. I. Efficient Production of Hydrogen by Photo-Induced Reforming of Glycerol at Ambient Conditions. Catal. Today 2009, 144, 75-80.

(12) Cargnello, M.; Gasparotto, A.; Gombac, V.; Montini, T.; Barreca, D.; Fornasiero, P. Photocatalytic $\mathrm{H}_{2}$ and Added-Value By-Products - The Role of Metal Oxide Systems in Their Synthesis from Oxygenates. Eur. J. Inorg. Chem. 2011, 2011, 4309-4323.

(13) Barreca, D.; Carraro, G.; Gombac, V.; Gasparotto, A.; Maccato, C.; Fornasiero, P.; Tondello, E. Supported Metal Oxide Nanosystems for Hydrogen Photogeneration: Quo Vadis? Adv. Funct. Mater. 2011, 21, 2611-2623.

(14) Gür, T. M.; Bent, S. F.; Prinz, F. B. Nanostructuring Materials for Solar-to-Hydrogen Conversion. J. Phys. Chem. C 2014, 118, 21301-21315.

(15) Lucht, K. P.; Mendoza-Cortes, J. L. Birnessite: A Layered Manganese Oxide To Capture Sunlight for Water-Splitting Catalysis. J. Phys. Chem. C 2015, 119, 22838-22846.

(16) Maruthapandian, V.; Pandiarajan, T.; Saraswathy, V.; Muralidharan, S. Oxygen Evolution Catalytic Behaviour of $\mathrm{Ni}$ Doped $\mathrm{Mn}_{3} \mathrm{O}_{4}$ in Alkaline Medium. $R S C A d v$. 2016, 6, 48995-49002.

(17) Strataki, N.; Bekiari, V.; Kondarides, D. I.; Lianos, P. Hydrogen Production by Photocatalytic Alcohol Reforming Employing Highly Efficient Nanocrystalline Titania Films. Appl. Catal., B 2007, 77, 184-189.

(18) Artioli, G. A.; Mancini, A.; Barbieri, V. R.; Quattrini, M. C.; Quartarone, E.; Mozzati, M. C.; Drera, G.; Sangaletti, L.; Gombac, V.; Fornasiero, P.; Malavasi, L. Correlation between Deposition Parameters and Hydrogen Production in $\mathrm{CuO}$ Nanostructured Thin Films. Langmuir 2016, 32, 1510-1520.

(19) Carraro, G.; Barreca, D.; Bekermann, D.; Montini, T.; Gasparotto, A.; Gombac, V.; Maccato, C.; Fornasiero, P. Supported F-Doped $\alpha-\mathrm{Fe}_{2} \mathrm{O}_{3}$ Nanomaterials: Synthesis, Characterization and Photo-Assisted $\mathrm{H}_{2}$ Production. J. Nanosci. Nanotechnol. 2013, 13, 4962-4968.

(20) Carraro, G.; Gasparotto, A.; Maccato, C.; Gombac, V.; Rossi, F.; Montini, T.; Peeters, D.; Bontempi, E.; Sada, C.; Barreca, D.; Fornasiero, P. Solar $\mathrm{H}_{2}$ Generation via Ethanol Photoreforming on $\varepsilon-\mathrm{Fe}_{2} \mathrm{O}_{3}$ Nanorod Arrays Activated by Ag and Au Nanoparticles. RSC Adv. 2014, 4, 32174-32179. 
(21) Gasparotto, A.; Barreca, D.; Bekermann, D.; Devi, A.; Fischer, R. A.; Fornasiero, P.; Gombac, V.; Lebedev, O. I.; Maccato, C.; Montini, T.; Van Tendeloo, G.; Tondello, E. FDoped $\mathrm{Co}_{3} \mathrm{O}_{4}$ Photocatalysts for Sustainable $\mathrm{H}_{2}$ Generation from Water/Ethanol. J. Am. Chem. Soc. 2011, 133, 19362-19365.

(22) Shrestha, S.; Dutta, P. K. Photochemical Water Oxidation by Manganese Oxides Supported on Zeolite Surfaces. ChemistrySelect 2016, 1, 1431-1440.

(23) Ray, C.; Pal, T. Recent Advances of Metal-Metal Oxide Nanocomposites and their Tailored Nanostructures in Numerous Catalytic Applications. J. Mater. Chem. A 2017, 5, 9465-9487.

(24) Roger, I.; Symes, M. D. First Row Transition Metal Catalysts for Solar-Driven Water Oxidation Produced by Electrodeposition. J. Mater. Chem. A 2016, 4, 6724-6741.

(25) Carraro, G.; Maccato, C.; Gasparotto, A.; Montini, T.; Turner, S.; Lebedev, O. I.; Gombac, V.; Adami, G.; Van Tendeloo, G.; Barreca, D.; Fornasiero, P. Enhanced Hydrogen Production by Photoreforming of Renewable Oxygenates through Nanostructured $\mathrm{Fe}_{2} \mathrm{O}_{3}$ Polymorphs. Adv. Funct. Mater. 2014, 24, 372-378.

(26) Mattos, L. V.; Jacobs, G.; Davis, B. H.; Noronha, F. B. Production of Hydrogen from Ethanol: Review of Reaction Mechanism and Catalyst Deactivation. Chem. Rev. 2012, 112, 4094-4123.

(27) Kuo, C. H.; Mosa, I. M.; Poyraz, A. S.; Biswas, S.; E-Sawy, A. M.; Song, W. Q.; Luo, Z.; Chen, S. Y.; Rusling, J. F.; He, J.; Suib, S. L. Robust Mesoporous Manganese Oxide Catalysts for Water Oxidation. ACS Catal. 2015, 5, 1693-1699.

(28) Naeem, R.; Ehsan, M. A.; Yahya, R.; Sohail, M.; Khaledi, H.; Mazhar, M. Fabrication of Pristine $\mathrm{Mn}_{2} \mathrm{O}_{3}$ and $\mathrm{Ag}-\mathrm{Mn}_{2} \mathrm{O}_{3}$ Composite Thin Films by AACVD for Photoelectrochemical Water Splitting. Dalton Trans. 2016, 45, 14928-14939.

(29) Boppana, V. B. R.; Yusuf, S.; Hutchings, G. S.; Jiao, F. Nanostructured Alkaline-CationContaining $\delta-\mathrm{MnO}_{2}$ for Photocatalytic Water Oxidation. Adv. Funct. Mater. 2013, 23, 878-884.

(30) Ramírez, A.; Hillebrand, P.; Stellmach, D.; May, M. M.; Bogdanoff, P.; Fiechter, S. Evaluation of $\mathrm{MnO}_{\mathrm{x}}, \mathrm{Mn}_{2} \mathrm{O}_{3}$, and $\mathrm{Mn}_{3} \mathrm{O}_{4}$ Electrodeposited Films for the Oxygen Evolution Reaction of Water. J. Phys. Chem. C 2014, 118, 14073-14081. 
(31) Yu, M. Q.; Li, Y. H.; Yang, S.; Liu, P. F.; Pan, L. F.; Zhang, L.; Yang, H. G. $\mathrm{Mn}_{3} \mathrm{O}_{4}$ Nano-Octahedrons on Ni Foam as an Efficient Three-Dimensional Oxygen Evolution Electrocatalyst. J. Mater. Chem. A 2015, 3, 14101-14104.

(32) Jeon, H. S.; Ahn, S. J.; Jee, M. S.; Yoon, S. S.; Hwang, Y. J.; Min, B. K. Water Oxidation by Manganese Oxide Electrocatalytic Films Synthesized by Chemical Solution Deposition Method. J. Electrochem. Soc. 2016, 163, F3113-F3118.

(33) Alzahrani, S. A.; Al-Thabaiti, S. A.; Al-Arjan, W. S.; Malik, M. A.; Khan, Z. Preparation of Ultra Long $\alpha-\mathrm{MnO}_{2}$ and $\mathrm{Ag} @ \mathrm{MnO}_{2}$ Nanoparticles by Seedless Approach and Their Photocatalytic Performance. J. Mol. Struct. 2017, 1137, 495-505.

(34) Chen, Z.; Jiao, Z.; Pan, D.; Li, Z.; Wu, M.; Shek, C.-H.; Wu, C. M. L.; Lai, J. K. L. Recent Advances in Manganese Oxide Nanocrystals: Fabrication, Characterization, and Microstructure. Chem. Rev. 2012, 112, 3833-3855.

(35) Liu, G. Y.; Hall, J.; Nasiri, N.; Gengenbach, T.; Spiccia, L.; Cheah, M. H.; Tricoli, A. Scalable Synthesis of Efficient Water Oxidation Catalysts: Insights into the Activity of Flame-Made Manganese Oxide Nanocrystals. ChemSusChem 2015, 8, 4162-4171.

(36) Robinson, D. M.; Go, Y. B.; Mui, M.; Gardner, G.; Zhang, Z.; Mastrogiovanni, D.; Garfunkel, E.; Li, J.; Greenblatt, M.; Dismukes, G. C. Photochemical Water Oxidation by Crystalline Polymorphs of Manganese Oxides: Structural Requirements for Catalysis. $J$. Am. Chem. Soc. 2013, 135, 3494-3501.

(37) Jin, W.; Han, X. J.; He, Y. Z.; Zhang, B.; Xu, P.; Du, Y. C. Galvanic Replacement Mediated Synthesis of $\mathrm{rGO}-\mathrm{Mn}_{3} \mathrm{O}_{4}$-Pt Nanocomposites for the Oxygen Reduction Reaction. RSC Adv. 2016, 6, 89124-89129.

(38) Fei, Z.-Y.; Sun, B.; Zhao, L.; Ji, W.-J.; Au, C.-T. Strong Morphological Effect of $\mathrm{Mn}_{3} \mathrm{O}_{4}$ Nanocrystallites on the Catalytic Activity of $\mathrm{Mn}_{3} \mathrm{O}_{4}$ and $\mathrm{Au} / \mathrm{Mn}_{3} \mathrm{O}_{4}$ in Benzene Combustion. Chem. Eur. J. 2013, 19, 6480-6487.

(39) Acharyya, S. S.; Ghosh, S.; Sharma, S. K.; Bal, R. Fabrication of Ag Nanoparticles Supported on One-Dimensional (1D) $\mathrm{Mn}_{3} \mathrm{O}_{4}$ Spinel Nanorods for Selective Oxidation of Cyclohexane at Room Temperature. New J. Chem. 2016, 40, 3812-3820.

(40) Liu, J. J.; Liu, J. Z.; Song, W. W.; Wang, F.; Song, Y. The Role of Electronic Interaction in the Use of $\mathrm{Ag}$ and $\mathrm{Mn}_{3} \mathrm{O}_{4}$ Hybrid Nanocrystals Covalently Coupled with Carbon as Advanced Oxygen Reduction Electrocatalysts. J. Mater. Chem. A 2014, 2, 17477-17488. 
(41) Frydendal, R.; Seitz, L. C.; Sokaras, D.; Weng, T. C.; Nordlund, D.; Chorkendorff, I.; Stephens, I. E. L.; Jaramillo, T. F. Operando Investigation of Au-MnO $\mathrm{M}_{\mathrm{x}}$ Thin Films with Improved Activity for the Oxygen Evolution Reaction. Electrochim. Acta 2017, 230, 2228.

(42) Mattelaer, F.; Bosserez, T.; Ronge, J.; Martens, J. A.; Dendooven, J.; Detavernier, C. Manganese Oxide Films with Controlled Oxidation State for Water Splitting Devices Through a Combination of Atomic Layer Deposition and Post-Deposition Annealing. $R S C A d v$. 2016, 6, 98337-98343.

(43) Pattern $\mathrm{N}^{\circ}$ 024-0734, JCPDS (2000).

(44) Piella, J.; Merkoci, F.; Genc, A.; Arbiol, J.; Bastus, N. G.; Puntes, V. Probing the Surface Reactivity of Nanocrystals by the Catalytic Degradation of Organic Dyes: The Effect of Size, Surface Chemistry and Composition. J. Mater. Chem. A 2017, 5, 11917-11929.

(45) http://srdata.nist.gov/xps.

(46) Chen, X.; Liu, L.; Yu, P. Y.; Mao, S. S. Increasing Solar Absorption for Photocatalysis with Black Hydrogenated Titanium Dioxide Nanocrystals. Science 2011, 331, 746-750.

(47) Qian, K.; Sweeny, B. C.; Johnston-Peck, A. C.; Niu, W. X.; Graham, J. O.; DuChene, J. S.; Qiu, J. J.; Wang, Y. C.; Engelhard, M. H.; Su, D.; Stach, E. A.; Wei, W. D. Surface Plasmon-Driven Water Reduction: Gold Nanoparticle Size Matters. J. Am. Chem. Soc. 2014, 136, 9842-9845.

(48) Brongersma, M. L.; Halas, N. J.; Nordlander, P. Plasmon-Induced Hot Carrier Science and Technology. Nat. Nanotechnol. 2015, 10, 25.

(49) Armelao, L.; Barreca, D.; Bottaro, G.; Gasparotto, A.; Gross, S.; Maragno, C.; Tondello, E. Recent trends on nanocomposites based on $\mathrm{Cu}, \mathrm{Ag}$ and $\mathrm{Au}$ clusters: A closer look. Coord. Chem. Rev. 2006, 250, 1294-1314.

(50) Shimura, K.; Yoshida, H. Heterogeneous Photocatalytic Hydrogen Production from Water and Biomass Derivatives. Energy Environ. Sci. 2011, 4, 2467-2481.

(51) Attia, Y. A.; Buceta, D.; Requejo, F. G.; Giovanetti, L. J.; Lopez-Quintela, M. A. Photostability of Gold Nanoparticles with Different Shapes: The Role of Ag Clusters. Nanoscale 2015, 7, 11273-11279. 
2

3

4

5

6

7

8

9

10

11

12

13

14

15

16

17

18

19

20

21

22

23

24

25

26

27

28

29

30

31

32

33

34

35

36

37

38

39

40

41

42

43

44

45

46

47

48

49

50

51

52

53

54

55

56

57

58

59

60

ACS Paragon Plus Environment 


\section{Table of Contents (TOC)}

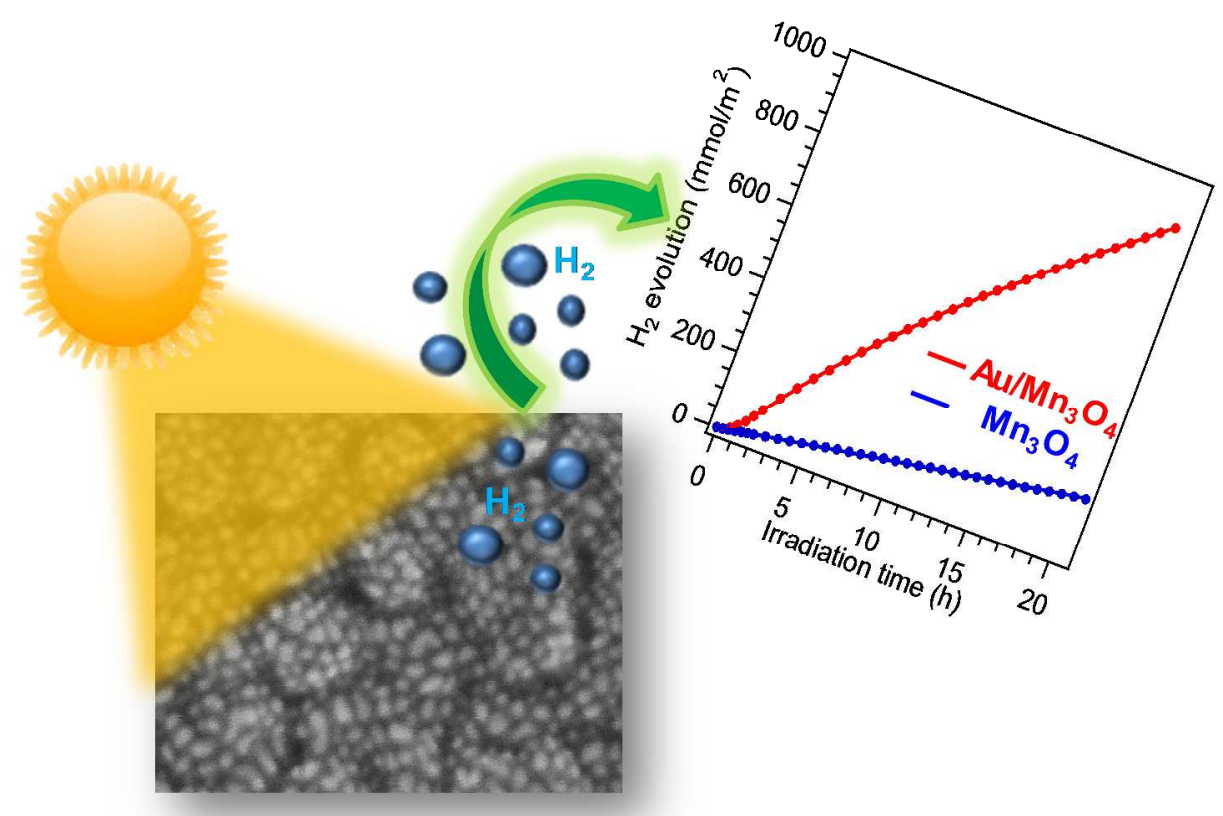

